\title{
The indirect McCollough effect: An examination of an associative account
}

\author{
G. KEITH HUMPHREY, ANDREW M. HERBERT, STEPHANIE HAZLEWOOD, \\ and JEFFREY A. D. STEWART \\ University of Western Ontario, London, Ontario, Canada
}

\begin{abstract}
It has been found that viewing, for example, a red-and-black vertical grating alternating with a green homogeneous field produces a color aftereffect-a McCollough effect-on a black-and-white vertical grating (i.e., green). Viewing such colored patterns also produces an aftereffect on a noninduced horizontal grating (i.e., pink) - the indirect McCollough effect. Humphrey, Dodwell, and Emerson (1989) argued that the indirect McCollough effect is caused by opponent properties of the visual system that organize the processing of contour and color along contrasting, probably orthogonal, dimensions. Recently, however, their interpretation of the indirect McCollough effect has been challenged by some findings of Eissenberg, Allan, Siegel, and Petrov (1995). These researchers have proposed that the indirect McCollough effect, like the McCollough effect, can be explained by associative principles. The results reported here question crucial aspects of the hypothesis of Eissenberg et al.
\end{abstract}

Color aftereffects contingent on contour orientation were first reported by Celeste McCollough (1965). To induce a McCollough effect (ME), two differently colored and oriented grating patterns (such as a red-and-black vertical grating and a green-and-black horizontal grating) are viewed alternately for a few seconds each over several minutes. After such viewing, white sections of a black-and-white vertical test grating appear to be tinted green, whereas the white sections of a horizontal test grating appear pink. If, however, the test patterns are rotated $45^{\circ}$ from the adapted orientations, color aftereffects are not reported.

Since McCollough's (1965) original report, numerous studies of the aftereffect have confirmed and extended her initial findings (for review, see Humphrey, 1998; Skowbo, Timney, Gentry, \& Morant, 1975; Stromeyer, 1978). One interesting extension of McCollough's original finding was reported by Stromeyer (1969). Stromeyer examined the possibility of inducing an ME with only one colored grating. In one experiment, presentation of a chromatic grating, such as a red vertical grating, was alternated with presentation of a colorless (black) field. An aftereffect was reported on both an achromatic test grating at the same orientation as the induction grating

This research was supported by a Research Grant from the Natural Sciences and Engineering Council of Canada to G.K.H. We thank Diane Skowbo for suggesting the comparative analysis of the three experiments and for her decisive and insightful comments on an earlier draft of the paper. Thanks also to two anonymous reviewers and to the editor, Robert O'Shea, for their helpful suggestions and comments. A.M.H. is now at École d'optométrie. Université de Montréal, Montréal, Quebec, Canada. J.A.D.S. is now at Queens University, Kingston, Ontario, Canada. Correspondence should be addressed to G. K. Humphrey, Department of Psychology, University of Western Ontario, London, ON, N6A 5C2 Canada (e-mail: keith (ajulian.uwo.ca) and on an orthogonal (i.e., horizontal) noninduced achromatic grating. The aftereffect color on the induced test grating was approximately complementary to that of the induction color (i.e., verticals now appeared greenish), as would be expected from the ME. The aftereffect color on the orthogonal noninduced grating was a very desaturated hue similar to that of the induction color (i.e., the horizontal grating now appeared pinkish). The color aftereffect on a noninduced orthogonally oriented pattern has since been referred to as the "indirect McCollough effect" (IME) by Dodwell and Humphrey (1990).

Since Stromeyer's (1969) report, several studies have been conducted in an attempt to replicate and extend his findings. MacKay and MacKay (1977) were unable to induce an IME when a colored induction grating was alternated with a black field. Ambler and Foreit (1978) also did not find an IME with alternation of a colored grating with a black field. There was, however, a trend toward an IME when a chromatic induction grating was alternated with a homogeneous field of the complementary color to that of the induction grating. Humphrey, Dodwell, and Emerson $(1985,1989)$ were more successful, however, in extending Stromeyer's initial observations. Humphrey et al. (1985) found that after induction with a pair of nonorthogonal patterns in complementary colors, such as red concentric circles and a green horizontal grating, a number of observers reported the expected MEs on the inducing patterns but they also reported IMEs on noninduced orthogonal patterns. In this case, subjects reported not only that concentric circle patterns appeared green and horizontal gratings appeared red, but also that radial line patterns appeared red and vertical gratings appeared green. Humphrey et al. (1989) followed up on their 1985 findings and found a significant IME when they alternated a single colored pattern with a homogeneous field of a complementary 
color, but not when they alternated with a colorless field. However, Allan and Siegel (1991) found evidence for the IME both when they alternated colored gratings with a black field and when the alternated them with a complementary colored field. Wolfe and Roorda (1990) also found an IME when they alternated a chromatic induction grating with a black field.

Humphrey et al. (1989; see also Dodwell \& Humphrey, 1990) explained the IME by proposing that orientation coding acts in an opponent manner somewhat analogous to that of color. Thus, when a subject fixates on a grating at a certain orientation, neural mechanisms that respond maximally to that orientation become fatigued, as do mechanisms that code for color after prolonged exposure to a particular color. When the grating is removed, the opponent process serves to create a relative increase in signals from mechanisms that respond maximally to a grating at an orthogonal orientation, thus creating an antagonistic rebound at the orthogonal orientation (Grossberg, 1980). Humphrey et al. (1989) contended that this orthogonal rebound is paired with the complementary colored homogeneous field that is alternated with the chromatic grating and could serve as the basis of the IME induction. Humphrey et al. (1989) also proposed that the IME could result from the hypothesized antagonistic rebound being paired with a colored afterimage. Others (e.g., Murch \& Hirsh, 1972) have found that afterimages can serve as the colored stimulus to support an ME. Alternating a single chromatic grating with a black field might produce an IME if the rebound in contour coding were paired with the afterimage color of the chromatic grating. Humphrey et al. (1989) did not observe IMEs under such induction conditions, but it may be that their color labeling measurement procedure was not sensitive enough to detect them.

Recently, Eissenberg, Allan, Siegel, and Petrov (1995; see also Allan, Siegel, Eissenberg, \& Thomas, 1997) have suggested that the IME is not actually an "indirect" effect at all. As noted, to induce an IME, one may present, for example, a green-and-black vertical grating alternated with a homogeneously colored field, such as a magenta square on a black background. This produces an expected $\mathrm{ME}$ on an achromatic vertical grating (i.e., pink) as well as an IME on a noninduced horizontal grating (i.e., green). However, Eissenberg et al. found that testing with the field alone (i.e., a white square on a black background) also elicited a color aftereffect-- the square appeared to have a greenish tinge. On the basis of associative learning principles, Eissenberg et al., have suggested that this result is a "direct" ME to the form of the homogeneous field ( form being defined as the shape of the frame surrounding the colored and/or patterned region). According to their account, presentation of a black-and-white horizontal grating in the same shaped form as that seen during induction produces a colored aftereffect because of the "direct" ME to the form, not because of the activity of orthogonal orientation coding mechanisms, as suggested by Humphrey et al. (1989; see also Dodwell \& Humphrey, 1990).

Much of the associative account of the IME offered by Eissenberg et al. (1995) appears to depend on particular induction conditions that will lead to color aftereffects on the shapes that make up the stimulus form and the shading of the region surrounding the patterns (the "frame lightness," in their terminology). Eissenberg et al. examined the effects of frame lightness on the strength of the IME (Experiments 3 and 4), but they did not intentionally vary form. The account of the IME offered by Eissenberg and colleagues should predict that if there is no ME induced on a form, there should be no IME. One procedure that could lead to the lack of a form effect is the alternation of a colored grating with a black field, and, as reviewed above, the first demonstration of the IME by Stromeyer (1969) used just such induction conditions - a red grating was alternated with a black field. Wolfe and Roorda (1990) and Allan and Siegel (1991, Experiment 3) have also reported such a result using a similar induction procedure. Perhaps in these experiments a form effect was produced by an afterimage of the induction grating on the black field. On the other hand, Ambler and Foreit (1978), MacKay and MacKay (1977), and Humphrey et al. (1989) did not obtain IMEs when a colored grating was alternated with a black field. There must have been no form effects in these latter studies according to the Eissenberg et al. account of the IME. It is difficult to know why an IME was obtained in some instances but not in others given the variety of methodological differences in the different studies.

In the experiments reported here, we attempted to replicate the results of Eissenberg et al. (1995) and extend them in order to test some predictions of the associative account of the IME. Experiment 1 replicated some aspects of Eissenberg et al., and thus tested the sensitivity of their methodology of inducing and measuring the IME. In Experiment 2, we examined subjects' responses to test stimuli following induction to a colored grating alternated with a blank (black) field. Experiment 3 repeated Experiment 1; however, the grating alternated with a larger (rectangular) solid magenta field, rather than a magenta disk of the same size, as the inducing and test gratings. Thus, in Experiments 2 and 3, we examined the effects of varying the form on induction of the IME.

\section{EXPERIMENT 1}

In the first experiment, we sought to establish the presence of the IME under induction and testing conditions similar to those used by Eissenberg et al. (1995) as a first step in evaluating some predictions of their associative account of the IME.

\section{Method}

Subjects. Eight subjects participated in the experiment. Five were male and 3 were female. All subjects had normal or conrected- 
to-normal vision and did not report any color vision abnormalities. Four of the subjects were naive to the nature of the experiment, but had previous experience in psychophysical tasks, and the other 4 subjects were the authors. The subjects ranged in age from 22 to 45 years.

Design. Identical pretests and posttests were administered before and after adaptation. The tests consisted of 250 trials presented in a different random order to each subject. In each trial, a grating at vertical, horizontal, or $45^{\circ}$ to either side of vertical, or a homogeneous disk was presented. There was a black fixation point in the middle of each pattern. Each of the patterns was presented in one of five different colors on each trial. The five colors were a desaturated pink, a very desaturated pink, achromatic (white), a desaturated green, and a very desaturated green. Each color $\times$ pattern $(5$ $\times 5$ ) trial was presented 10 times. The pretest performance established a baseline measure against which the posttest scores were compared to evaluate shifts in color perception for all subjects.

The induction phase of the experiment consisted of exposing subjects to a green vertical and black grating alternating with a magenta homogeneous field every $3 \mathrm{sec}$ for $23 \mathrm{~min}$. The interstimulus interval was $1 \mathrm{sec}$.

Apparatus. An Apple Macintosh Ilci microcomputer with an Apple 14-in. high-resolution color monitor controlled stimulus presentation and response recording. The subject was seated $104 \mathrm{~cm}$ from the monitor and head movements were constrained by a chinrest equipped with a forehead stop and two lateral head stops. The stimuli presented were either square wave gratings in a circular field or homogeneous disks $6.2 \mathrm{~cm}$ in diameter subtending a visual angle of $3.4^{\circ}$. The fundamental spatial frequency of the grating was $3.1 \mathrm{cycles} / \mathrm{degree}$. Each stimulus was presented individually in the center of the monitor screen against a black background.

Luminance and chromaticity were measured with a Minolta Chroma Meter CS-100. The chromaticity values (CIE $x$ - and $y$ coordinates) and luminance values $\left(\mathrm{cd} / \mathrm{m}^{2}\right)$ of adaptation and test stimuli are presented in Table 1.

Procedure. Subjects were tested in a darkened room. In the pretest and posttest portions of the experiment, subjects were asked to fixate on a black point in the center of the stimuli and respond as to whether the stimuli appeared greenish or pinkish. Subjects made responses by pressing either a "green key" or "pink key" specified on the Macintosh keyboard. This provided baseline data and allowed the responses to be examined for any residual aftereffect from previous inductions.

Once the pretest was completed (which took approximately $10 \mathrm{~min}$ ), the subject underwent the 23 -min induction procedure. Again, a fixation point was presented and the subject was asked to fixate on this point for the duration of the induction. After induction, the subject was exposed to normal room lights for a period of $10 \mathrm{~min}$ to ensure that no complementary negative afterimages persisted as a result of retinal fatigue. A posttest was then administered to assess a shift in color perception. The posttest was administered in an identical manner to the pretest.

Table 1

Luminance Values $\left(\mathrm{cd} / \mathrm{m}^{2}\right)$ and Chromaticity Values (CIE $x$ - and $y$-Coordinates) for the Colors in Adaptation and Baseline/Test

\begin{tabular}{lccc}
\hline \multicolumn{1}{c}{ Color } & Luminance & $x$ & $y$ \\
\hline Induction & & & \\
Green & 27.7 & .299 & .588 \\
Magenta & 11.1 & .399 & .220 \\
Pretest/Posttest & & & \\
Light green & 42.1 & .285 & .302 \\
Lightest green & 42.6 & .284 & .297 \\
White & 43.5 & .284 & .293 \\
Lightest magenta & 42.1 & .284 & .289 \\
Light magenta & 40.9 & .284 & .285 \\
\hline
\end{tabular}

\section{Results}

Figure 1 shows the number of green responses made during pre- and posttest for the five different patterns. The numbers of green responses made during the pretest were similar for the five patterns; typically the subjects made approximately 25 green responses to each of the patterns presented during the pretest. This suggests that the colors of the test patterns were accurately perceived and that there was no response bias. The number of green responses made for both the horizontally oriented grating and the disk showed an increase during the posttest. A large decrease in the number of green responses made to the vertically oriented grating (which was presented in green during induction) was evident during the posttest. The number of green responses made for the obliquely oriented gratings $\left(45^{\circ}\right.$ and $\left.-45^{\circ}\right)$ showed little change from pretest to posttest.

To assess quantitatively any shifts that may have occurred in the number of green responses made between pre- and posttest, the mean number of green responses, over the five test colors, was subjected to a 2 (assessment phase: pretest or posttest) $\times 5$ (pattern: vertical, horizontal, $45^{\circ}$, and $-45^{\circ}$ gratings, and the disk) repeated measures analysis of variance (ANOVA). There was a significant main effect of test pattern $[F(4,7)=39.5$, $\left.M S_{\mathrm{e}}=1,499.98, p<.001\right]$. There was also a significant interaction of stimulus pattern and test phase $[F(4,28)=$ $\left.43.21, M S_{\mathrm{e}}=821.52, p<.001\right]$. Simple effects analyses were conducted to explore the interaction. The analyses indicated that the mean number of green responses to the patterns during the pretest assessment did not differ significantly $\left[F(4,28)=1.63, M S_{\mathrm{e}}=37.2, p=.20\right]$, but they did differ significantly during the posttest $[F(4,28)=$ $\left.114.36, M S_{\mathrm{e}}=19.77, p<.001\right]$.

Further simple effects analyses were conducted on the pretest versus posttest differences for each test pattern. For the vertically oriented patterns, significantly fewer green responses were made during the posttest than during the pretest $\left[F(1,7)=46.28, M S_{\mathrm{e}}=40.420, p<.001\right]$. Significantly more green responses were made for the horizontally oriented patterns during the posttest than were made during the pretest $\left[F(1,7)=43.43, M S_{\mathrm{e}}=\right.$ $13.82, p<.001]$. Also, significantly more green responses were made for the disk during the posttest than during the pretest $\left[F(1,7)=71.27, M S_{\mathrm{e}}=11.00, p<.001\right]$. However, the number of green responses made for the patterns with oblique orientations $\left(45^{\circ}\right.$ and $\left.-45^{\circ}\right)$ during the posttest were not significantly different from the number made during the pretest $\left[F(1,7)=1.78, M S_{\mathrm{e}}=11.39\right.$, $p=.22]$.

\section{Discussion}

The results replicate those of others who have found an IME to a grating that is orthogonal to the orientation of the induction grating (Allan \& Siegel, 1991; Eissenberg et al., 1995; Humphrey et al.. 1985, 1989; Stromeyer, 1969; Wolfe \& Roorda, 1990). They also replicate the findings of Eissenberg et al. in that there was 


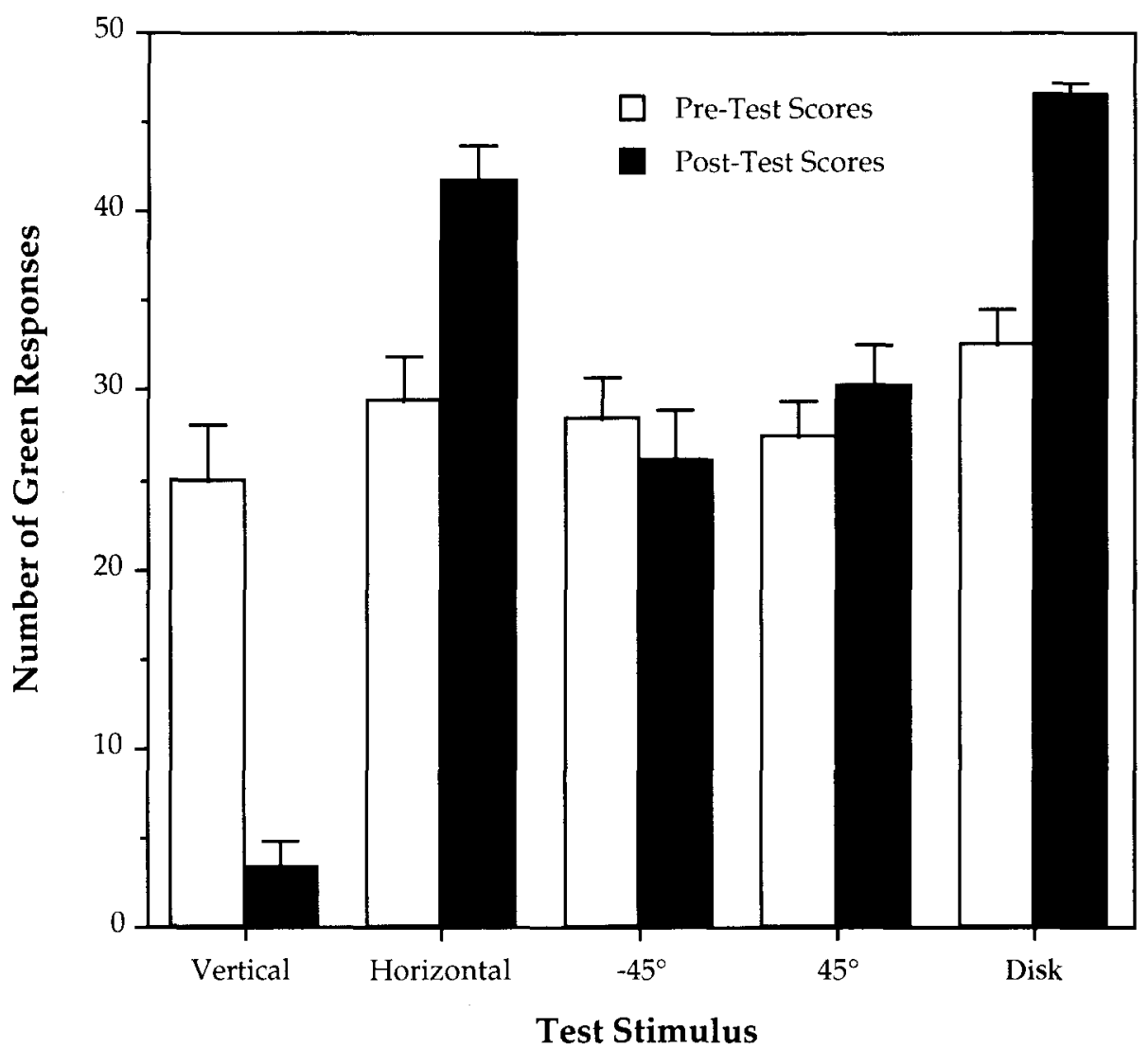

Figure 1. The mean number of green responses for pre- and posttests for all test stimuli for Experiment 1. Error bars indicate $+1 S E M$.

a significant color aftereffect for the form. The possible cause of the latter effect is considered in the General Discussion.

There was no pre- to posttest shift in the number of color responses to the oblique gratings, indicating no aftereffect, as has been found by others (Allan \& Siegel, 1991; Eissenberg et al., 1995; Humphrey et al., 1989). According to the account of the IME given by Humphrey et al. (1989; see also Dodwell \& Humphrey, 1990), one should not expect an effect on the oblique gratings because the proposed orientation opponency underlying the IME works in orthogonal pairs.

One might ask why there should not be an effect on the oblique gratings according to the hypothesis of Eissenberg et al. (1995). Their account suggests that the IME is the result of the form effect that will also occur when the horizontal grating is viewed in the same form. The oblique gratings are also presented in this form. Eissenberg and colleagues have recognized that this could be problematic for their account, but they have results showing that the direct effect (the ME) is generalized to $45^{\circ}$ from the induced orientation after being induced with a single grating. After induction with a vertical green grating, for example, their results indicated that the ME generalized to $45^{\circ}$ and $-45^{\circ}$ test grat- ings. Like the vertical grating, these gratings were seen as pinkish. This pink aftereffect was weaker than the aftereffect on the vertical grating, but was strong enough to counteract the form effect (i.e., green). As a result, the form effect and the weak, generalized effect on the obliques opposed each other, leaving no net aftereffect. Thus, one cannot measure the strength of the aftereffect on oblique gratings because of the cancellation caused by the form.

The results of Eissenberg et al. (1995) and others (e.g., Ellis, 1977) suggest that there may be quite broad tuning of the ME after single pattern induction. Most studies, however, have shown that induction with a single grating leads to extremely weak or nonexistent effects at an orientation $45^{\circ}$ from the induction orientation (Allan \& Siegel, 1991; Ambler \& Foreit, 1978; Humphrey et al., 1989; MacKay \& MacKay, 1977). This lack of generalization occurred even when induction involved a single grating without an alternating field in complementary color. In this case, then, there should not be a counteracting effect of the test form since one was not used during induction. It could be that the assessment technique employed by Eissenberg et al. was more sensitive than that used in other studies. Allan and Siegel (1991: Experiment 2), however, also found that there was no statisti- 
cally reliable aftereffect on a grating $45^{\circ}$ from the induced orientation after induction with a single orientation alternating with a black screen, and the assessment technique used by Eissenberg et al. was very similar to that of Allan and Siegel. Further, it appears that the same stimulus color settings were used in the two sets of experiments (Eissenberg et al., 1995, p. 265). At present, much of the evidence shows that induction with a single grating produces MEs that are extremely weak or nonexistent at $45^{\circ}$ from the induced orientation. Given this evidence, it does not appear that the explanation proffered by Eissenberg et al. for the lack of an aftereffect on gratings $45^{\circ}$ from the induced gratings is supported, although further experimentation may be needed to decide the issue definitively.

\section{EXPERIMENT 2}

The account of the IME proposed by Eissenberg et al. (1995) suggests that the form (i.e., in the present experiment, the round contour of the disk shape) acts as a conditioned stimulus. Thus, the associative account would suggest that the occurrence of the IME should depend on having the same-shaped stimulus (the disk) associated with the effect present during induction so that a color aftereffect on the form can be induced. In the present experiment, we tested this prediction by presenting a blank (black) field during induction instead of presenting a uniform chromatic field within a form of a particular shape.

\section{Method}

Subjects. Seven of the subjects ( 4 males and 3 females) from Experiment 1 participated in Experiment 2. One male subject (nonnaive) was dropped from the final two experiments because he continued to perceive strong residual aftereffects during subsequent pretests.

Design. The pretest and posttest were similar to those used in Experiment 1. Because our main concern was with the IME, the oblique gratings were not tested so as to shorten the pre- and posttest phases of the experiment. The induction phase for this experiment required the subjects to fixate on a green-and-black vertical grating alternating with a blank (black) field. The timing of stimulus presentations and the interval between induction and posttest remained the same as in Experiment 1.

Apparatus and Materials. Response recording and stimulus presentation were controlled as in Experiment 1. The blank, rectangular field subtended $9.3^{\circ} \times 12.6^{\circ}$ of visual angle. The stimuli were positioned on the screen in the same manner as in Experiment 1 .

Procedure. The procedure used was the same as that in Experiment 1.

\section{Results}

A histogram relating the number of green responses made during pre- and posttest for the three different patterns is illustrated in Figure 2. The number of green responses made for the horizontally oriented grating increased from the pretest to posttest, whereas the number of green responses made for the vertically oriented grating (presented in green during induction) decreased from pretest to posttest. There was little change in the number of green responses made for the disk from the pretest to the posttest.

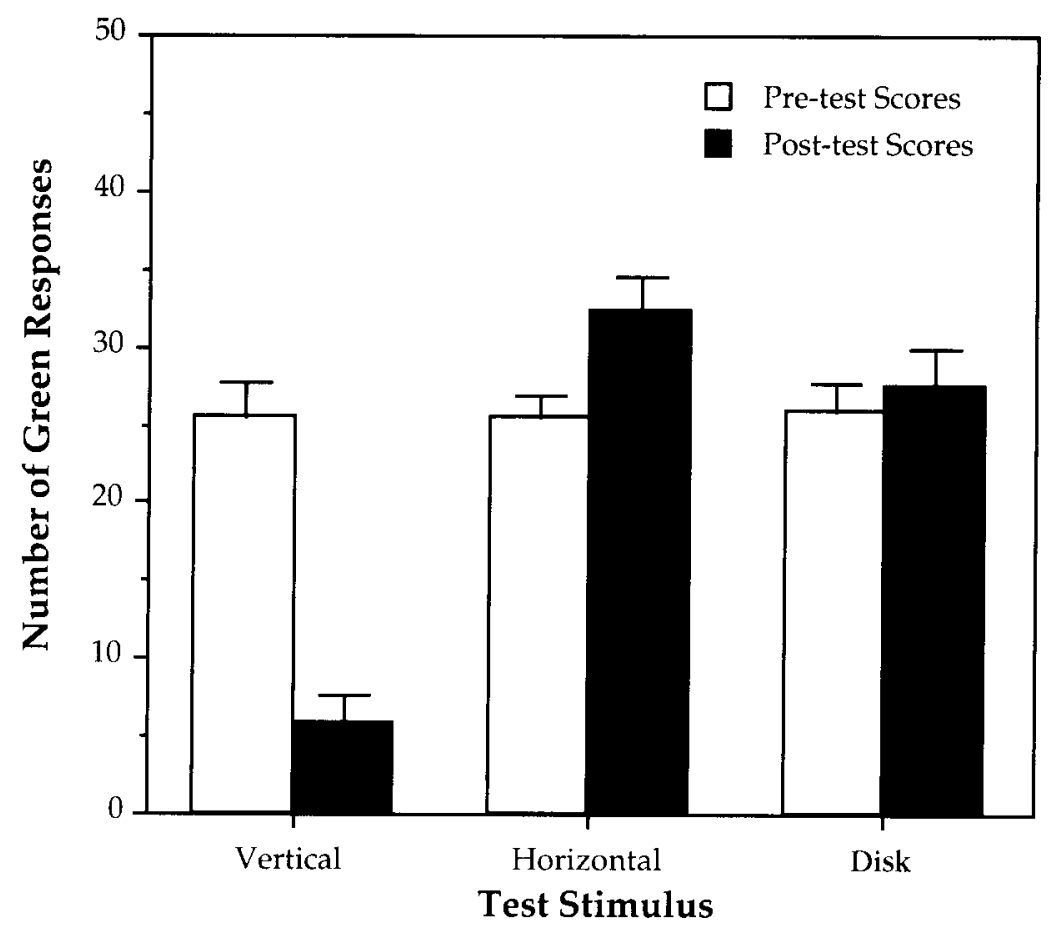

Figure 2. The mean number of green responses for pre- and posttests for all test stimuli for Experiment 2. Error bars indicate +1 SEM. 
The mean number of green responses, over the five test colors, was subjected to a 2 (assessment phase: pretest or posttest) $\times 3$ (pattern: vertical, horizontal, and the disk) repeated measures ANOVA. There was a significant main effect of test pattern $\left[F(2,6)=57.12, M S_{\mathrm{e}}=699.01\right.$, $p<.001]$. There was also a significant interaction of stimulus pattern and test phase $\left[F(2,12)=53.48, M S_{\mathrm{e}}=\right.$ $676.60, p<.001]$. Simple effects indicated that the mean number of green responses to the patterns during the pretest did not differ significantly $[F(2,12)<1]$, but they did differ significantly during the posttest $[F(2,12)=$ 94.36, $\left.M S_{\mathrm{e}}=14.57, p<.001\right]$.

Further simple effects analyses showed that significantly fewer green responses were made during the posttest than during the pretest for vertically oriented patterns $\left[F(1,6)=47.51, M S_{\mathrm{e}}=27.81, p<.001\right]$. Significantly more green responses were made for the horizontally oriented patterns during the posttest than during the pretest $\left[F(1,6)=17.814, M S_{\mathrm{e}}=9.24, p<.01\right]$. There was no significant change in the number of green responses made for the disk from pre- to posttest $[F(1,6)=$ $1.1, M S_{\mathrm{e}}=7.64, p<.33$ ].

\section{Discussion}

An IME to the grating orthogonal to the orientation of the induction stimulus was found during the present experiment. Furthermore, no significant effect for the form (the disk) was found for the present experiment. These results can be seen to pose some problems for the hypothesis of Eissenberg et al. (1995). The occurrence of the IME would be expected to depend on a direct ME on the disk (the form), according to their account. The IME was found in the absence of a disk effect in this case, so the IME cannot be a direct ME to the form, as suggested by Eissenberg et al. IMEs have been found by others using a similar induction paradigm to that used in the present experiment (Allan \& Siegel, 1991; Stromeyer, 1969; Wolfe \& Roorda, 1990), and it is certainly possible, and perhaps likely, that the IME found in these studies also occurred in the absence of a form effect. The present experiment shows clearly that the IME can occur in the absence of any form effect.

\section{EXPERIMENT 3}

In Experiment 3, we further examined the effects of form on the IME. We examined whether the aftereffect to the form depended on having a form presented during induction that was the same shape and size as that presented in the test phase. If a surrounding form of a shape and size different from that presented during the test phase is presented during induction, the form effect should disappear or decrease, according to the associative account of Eissenberg et al. (1995), and the IME should be similarly affected. In Experiment 3, we examined these issues by presenting a vertical green grating alternating with a larger, rectangular, uniform magenta field, rather than a magenta disk of the same size as the test gratings (as in Experiment 1).

\section{Method}

Subjects. The subjects were the same 4 males and 3 females who participated in Experiment 2.

Design. The pretest and posttest were identical to those used in Experiment 2. The induction phase for this experiment, however, required the subjects to fixate on a green-and-black vertical grating alternating with a large rectangular homogeneous magenta field. The presentation time for each pattern remained the same as in Experiments 1 and 2 .

Apparatus and Materials. Response recording and stimulus presentation were controlled as in Experiment 2. As before, the grating was presented within a circular aperture subtending $3.4^{\circ}$ of visual angle. The rectangular homogeneous field subtended $7.7^{\circ} \times$ $11^{\circ}$ of visual angle. The stimuli were positioned on the screen in the same manner as in Experiment 2.

Procedure. The procedure used was the same as that in Experiment 2.

\section{Results}

Figure 3 shows that the number of green responses made for both the horizontally oriented grating and the disk increased from the pretest to posttest. From the pretest to the posttest, the number of green responses made for the vertically oriented grating, which was presented in green during induction, decreased.

To assess color shifts from pre- to posttest, the mean number of green responses, over the five test colors, was subjected to a 2 (assessment phase: pretest or posttest) $x$ 3 (pattern: vertical, horizontal, and the disk) repeated measures ANOVA. There was a significant main effect of test pattern $\left[F(2,6)=74.15, M S_{\mathrm{e}}=1,702.01, p<\right.$ $.001]$. There was also a significant interaction of stimulus pattern and test phase $\left[F(2,12)=89.31 M S_{\mathrm{e}}=\right.$ $1,296.01, p<.001]$. Simple effects analyses indicated that the mean number of green responses to the patterns during the pretest did not differ significantly $[F(2,12)=$ $\left.1.94, M S_{\mathrm{e}}=19.22, p=.19\right]$, but they did differ significantly during the posttest $\left[F(2,12)=162.72, M S_{\mathrm{e}}=\right.$ $18.135, p<.001]$.

Further simple effects analyses showed that for vertically oriented patterns, significantly fewer green responses were made during the posttest than during the pretest $\left[F(1,6)=90.85, M S_{\mathrm{e}}=18.41, p<.001\right]$. Significantly more green responses were made for the horizontally oriented patterns during the posttest than during the pretest $\left[F(1,6)=34.606, M S_{\mathrm{e}}=10.405, p<\right.$ $.001]$. In addition, significantly more green responses were made for the disk during the posttest than during the pretest $\left[F(1,6)=14.69, M S_{\mathrm{e}}=36.81, p<.001\right]$.

\section{Discussion}

In the present experiment, the homogeneously colored region presented during the induction phase was surrounded by a form differing in both shape and size from the form presented in the test phase. Nevertheless, there was a measurable aftereffect to the disk, and an IME to 


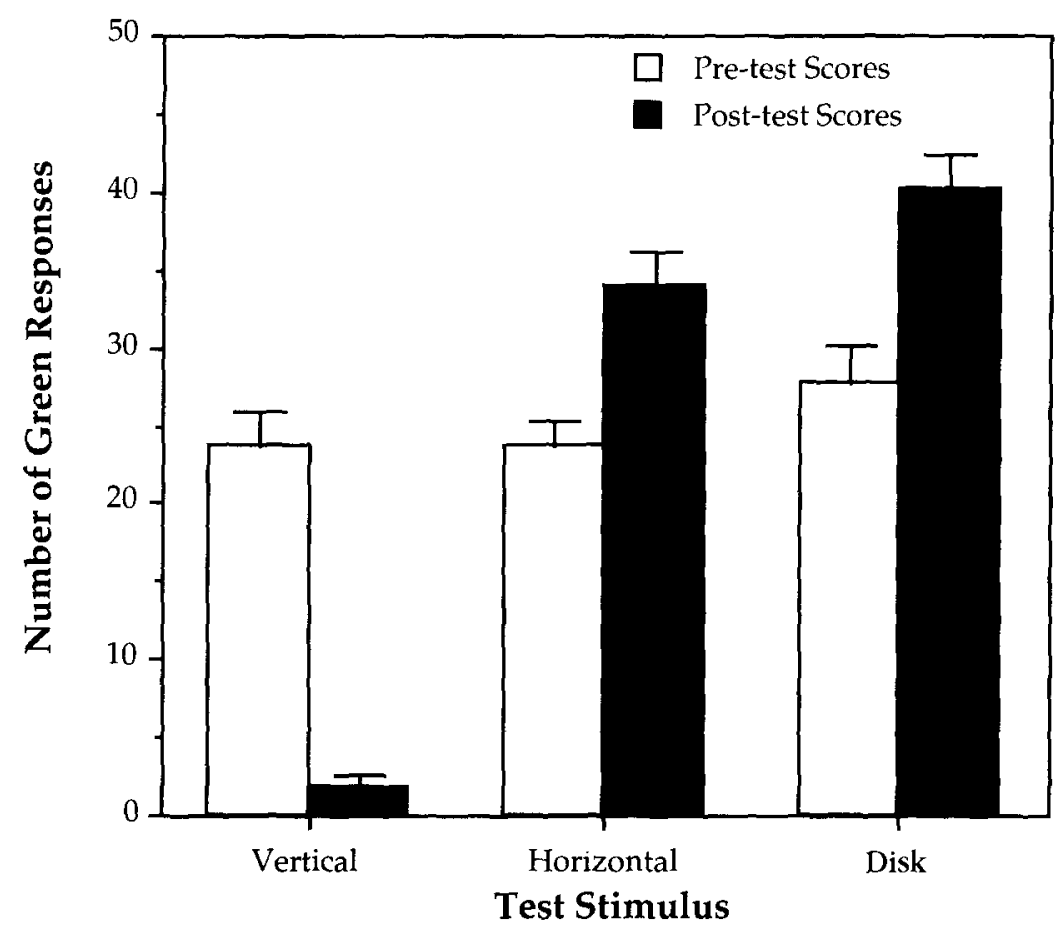

Figure 3. The mean number of green responses for pre- and posttests for all test stimuli for Experiment 3. Error bars indicate $+1 S E M$.

the horizontal grating despite the differences in the forms presented during the induction and test phases. These results are discussed at length in the General Discussion.

\section{COMPARISON OF EXPERIMENTS 1, 2, AND 3 RESULTS}

We compared the results of the three experiments to evaluate whether there were any changes in the strength of the ME, IME, or form effect as a function of induction conditions. To do this, we calculated difference scores (number of green responses postinduction minus number of green responses preinduction) for the vertical grating, horizontal grating, and disk for each of the 7 subjects who participated in all three experiments. Such difference scores help to normalize the results across experiments. These data were analyzed with a $3 \times 3$ withinsubjects ANOVA in which the factors were experiment and test pattern (vertical grating, horizontal grating, and form). There was an overall effect of experiment and test pattern, but, more importantly, there was an interaction between experiment and test pattern $[F(4,24)=3.9$, $\left.M S_{\mathrm{e}}=114.04, p<.02\right]$. Simple effects analyses showed that the strength of the ME (vertical test grating) was not statistically different across the three experiments. Similarly, the strength of the IME (horizontal test gratings) did not differ across the three experiments. In contrast, the disk effect differed significantly across the experiments. Newman-Keuls test showed that the form effect was less in Experiment 2 than in Experiments 1 and 3 (both $p \mathrm{~s}<.01$ ), but that the form effect did not differ be- tween Experiments 1 and 3. According to this comparative analysis, the presence/absence of the homogeneous chromatic field during induction did not have an impact on the strength of the ME or the IME, but it did have an impact on the disk effect.

\section{GENERAL DISCUSSION}

The purpose of the present experiments was to test some predictions of the associative account of Eissenberg et al. (1995). Experiment 1 served as a replication of the Eissenberg et al. study. The results of this experiment were consistent with the findings of Eissenberg et al. Both an ME and an IME were induced. Moreover, there was a significant color aftereffect on the disk. No color aftereffect was found for patterns oriented at $45^{\circ}$ and $-45^{\circ}$ to the orientation of the inducing pattern.

Experiment 2 served as a replication and extension of earlier experiments conducted by Allan and Siegel (1991), Wolfe and Roorda (1990), and Stromeyer (1969). The account of the IME offered by Eissenberg et al. (1995) suggested that the shape of the frame surrounding the induction pattern (the form) should act as a part of the conditioned stimulus. Most importantly, the results of Experiment 2 showed that subjects who were not exposed to the form during induction did not have an aftereffect to the form, but still experienced the IME. Further, the comparative analysis showed that the strength of the IME in this experiment did not differ from that observed in Experiments 1 and 3. These findings are contrary to the hypothesis of Eissenberg et al. 
Experiment 3 was an extension of Experiment 2. We examined the effect of a difference in the shape and size of the homogeneous field used during induction and that used during testing on the aftereffect to form. There was still a strong and reliable form effect and IME in this experiment. In one sense, then, the results from Experiment 3 are consistent with the associative account of Eissenberg et al. It is puzzling, however, why a form effect was obtained if the form effect is, as suggested by Eissenberg et al., an ME. The result is puzzling because a substantial amount of research would suggest that a color aftereffect to the disk would not be obtained in Experiment 3 because of the apparent retinotopic nature of the ME. For example, both Stromeyer and Dawson (1978) and Mahmud (1987) induced MEs with a pair of vertical gratings of the same spatial frequency (one red and black, the other green and black) that were presented sequentially in counterphase retinal positions. The aftereffect color was contingent on the phase (position) of the test grating. In another experiment, Stromeyer (1972) found that the ME weakened or disappeared when a test grating was moved to a different retinal area from the induced area. Results of other experiments also indicate that the ME is retinotopic (Broerse \& Grimbeek, 1994; Broerse \& O'Shea, 1995; Humphrey, Herbert, Symons, \& Kara, 1994; Humphrey, Skowbo, Symons, Herbert, \& Grant, 1994; for review, see Humphrey, 1998; Stromeyer, 1978), but Allan and Siegel (1997) and Siegel, Allan, \& Eissenberg $(1992,1994)$ have presented results suggesting that the $\mathrm{ME}$ is spatiotopic. It appears that much of the evidence favors a retinotopic account of the $\mathrm{ME}$, but there is certainly room for more research to decide this issue definitely.

In Experiment 3, the borders of the rectangular form and the disk did not correspond retinotopically, but subjects perceived color in the disk on the posttest. The disk effect observed in Experiment 3 is inconsistent with retinotopic descriptions of the ME. One possible account for this effect is that there is some overall shift in color balance that is not very closely tied to, or dependent on, a match between retinal contours in induction and test; in short, it is not a contingent aftereffect. Research by Jameson, Hurvich, and Varner (1979) suggests such a possibility. They found that viewing a colored light source alternating with a blank field produced a shift in perceived color that persisted for at least $15 \mathrm{~min}$ (no measurements were made beyond $15 \mathrm{~min}$ ). They attributed this retardation of recovery to a shift in baseline functions of the opponent processes of the red-green color channel at a central, as opposed to a peripheral, level. Their proposal does not depend on any form or contour contingencies. Hansel and Mahmud (1978) and Mahmud (1987) also reported on long-lasting color shifts after subjects had adapted to large homogeneous regions. They adapted subjects to homogeneous red and homogeneous green rectangular regions at two different retinal loci and obtained appropriate changes in perceived color (i.e., regions adapted to red appeared green and vice versa) on achromatic test re- gions 40 min later (and in 1 subject, $8 \mathrm{~h}$ later). They suggested that these changes are noncontingent, long-term negative afterimages. Further, Hansel and Mahmud ( $p$. 1604) noted that they obtained similar aftereffects after adapting with rectangular regions but testing with circular regions. Hansel and Mahmud and Mahmud also generated MEs in the same subjects in their experiments. On the basis of their results, they argued that MEs and longterm afterimages can be generated from the same retinal area and depend on different mechanisms.

The results of Jameson et al. (1979), Hansel and Mahmud (1978), and Mahmud (1987) all suggest that the aftereffects observed on the homogeneous fields are not contingent aftereffects. This suggestion is certainly consistent with our findings in Experiment 3. Nevertheless, it is important to note that Eissenberg et al. (1995; see also Allan \& Siegel, 1997, and Siegel et al., 1992) have proposed that it is not only the stimulus form, but also the frame lightness that underlies the color aftereffect. The large, rectangular field and small, circular test disk used in Experiment 3 had the same lightness according to the proposal of Siegel et al. (1992), since both were surrounded by a black field. Thus, the aftereffect may have resulted from the similar frame lightness in the rectangle and disk. Eissenberg et al. varied frame lightness and presented evidence that this affected the IME. Although we cannot address the issue of frame lightness in the present experiments, at the very least our results suggest that, under the conditions of our experiment, the form of the stimulus is irrelevant to the aftereffect found on homogeneous regions. Testing the limits and nature of such "form" aftereffects and deciding whether they are indeed MEs or not is a topic for further research.

Eissenberg et al. (1995) noted that although the results of their experiments are consistent with an associative account of the IME, some difficulties for the associative account can be found in the earlier research of Humphrey et al. $(1985,1989)$. As mentioned above, Humphrey et al. $(1985,1989)$ found that after induction with a pair of nonorthogonal patterns in complementary colors, such as red concentric circles and a green horizontal grating, observers reported the expected MEs on the inducing patterns but they also reported IMEs on noninduced orthogonal patterns. For example, subjects reported that concentric circles appeared green and horizontal gratings appeared red, but also that radial line patterns appeared red and vertical gratings appeared green. In these experiments, no form was present during induction that was necessary, according to Eissenberg et al.'s account, to support IMEs. Further, the test patterns used by Humphrey et al. $(1985,1989)$ were composed of either sections of induced patterns (i.e., concentric circle and horizontal grating segments) or of sections of noninduced patterns (i.e., radial line and vertical grating segments). If the IME is a result of a color aftereffect to a form, it is difficult to see why two different color aftereffects (IMEs) were reported on the same noninduced test patterns. Finally, the "frame lightness" was different be- 
tween induction and test conditions in the experiments of Humphrey et al. (1985, 1989).

The results of the present experiments are consistent with the account of the IME proposed by Humphrey et al. (1989; see also Dodwell \& Humphrey, 1990; Humphrey, 1998). The IME does not depend on a form effect, according to this hypothesis. For each induction condition used in the present series of experiments, both the ME and the IME were produced whether there was a resulting disk effect or not. Further research on the nature of the IME is needed, especially with regard to the effects observed in Experiment 3, but the present results question the hypothesis of Eissenberg et al. (1995).

\section{REFERENCES}

Allan, L. G., \& Siegel, S. (1991). Characteristics of the indirect McCollough effect. Perception \& Psychophysics, 50, 249-257.

Allan, L. G., \& SiEgel, S. (1997). Contingent color aftereffects: Reassessing old conclusions. Perception \& Psychophysics, 59, 129-141.

Allan, L. G., Siegel, S., Eissenberg, T., \& Thomas, S. E. (1997). More on the associative interpretation of the indirect McCollough effect. Quarterly Journal of Experimental Psychology, 50B, 332-349.

Ambler, B. A., \& Foreit, K. G. (1978). Induction of the McCollough effect II: Two different mechanisms. Perception \& Psychophysics, 24, 466-470.

Broerse, J., \& Grimbeek, P. (1994). Eye movements and the associative basis of contingent color aftereffects: A comment on Siegel, Allan, and Eissenberg (1992). Journal of Experimental Psychology: General, 123, 81-85.

Broerse, J., \& O'SheA, R. P. (1995). Local and global factors in spatially-contingent coloured aftereffects. Vision Research, 35, 207226.

Dodwell, P. C., \& Humphrey, G. K. (1990). A functional theory of the McCollough effect. Psychological Review, 97, 78-89.

Eissenberg, T., Allan, L. G., Siegel, S., \& Petrov, N. (1995). An associative interpretation of the indirect McCollough effect. Quarterly Journal of Experimental Psychology, 48B, 262-286.

Ellis, S. R. (1977). Orientation selectivity of the McCollough effect: Analysis by equivalent contrast transformation. Perception \& Psychophysics, 22, 539-544.

Grossberg, S. (1980). How does the brain build a cognitive code? Psychological Review, 87, 1-51.

Hansel, C. E. M., \& Mahmud, S. H. (1978). Comparable retention times for the negative colour afterimage and the McCollough effect. Vision Research, 18, 1601-1605.

Humphrey, G. K. (1998). The McCollough effect: Misperception and reality. In V. Walsh \& J. Kulikowsi (Eds.), Perceptual constancy: Why things look as they do (pp. 31-68). Cambridge: Cambridge University Press.

Humphrey, G. K., Dodwell, P. C., \& Emerson, V. F. (1985). The roles of pattern orthogonality and color contrast in the generation of patterncontingent color aftereffects. Perception \& Psychophysics, 38, 343353 .

Humphrey, G. K., Dodwell, P. C., \& Emerson, V. F. (1989). Patterncontingent color aftereffects on noninduced patterns. Perception \& Psychophysics, 45, 97-109.

Humphrey, G. K., Herbert, A. M., Symons, L. A., \& Kara, S. (1994). McCollough effect to form: A local phenomenon. Journal of Experimental Psychology: General, 123, 86-90.

Humphrey, G. K., Skowbo, D., Symons, L. A., Herbert, A. M., \& Grant, C. L. (1994). Text-contingent color-aftereffects: A reexamination. Perception \& Psychophysics, 56, 405-413.

JAMESON, D., HuRvich, L. M., \& VARNER, F. D. (1979). Receptoral and postreceptoral visual processes in recovery from chromatic adaptation. Proceedings of the National Academy of Sciences, 76, 30343038.

MaCKAY, D. M., \& MACKAY, V. (1977). Multiple orientation-contingent chromatic after-effects. Quarterly Journal of Experimental Psychology, 29, 203-218.

Marmud, S. H. (1987). Similar-orientation McCollough effect and the classical negative afterimage in a common adaptive process. Bulletin of the Psychonomic Society, 25, 455-457.

McCollough, C. (1965). Color adaptation of edge-detectors in the human visual system. Science, 149, 1115-1116.

MURCH, G. M., \& HiRSH, J. (1972). The McCollough effect created by complementary afterimages. American Journal of Psychology, 85, 241-247.

Siegel, S., Allan, L. G., \& Eissenberg, T. (1992). The associative basis of contingent color aftereffects. Journal of Experimental Psychology: General, 121, 79-94.

Siegel, S., Allan, L. G., \& Eissenberg, T. (1994). Scanning and formcontingent color aftereffects. Journal of Experimental Psychology: General, 123, 91-94.

Skowbo, D., Timney, B. N., Gentry, T. A., \& Morant, R. B. (1975). McCollough effects: Experimental findings and theoretical accounts. Psychological Bulletin, 82, 497-510.

Stromeyer, C. F., III (1969). Further studies of the McCollough effect. Perception \& Psychophysics, 6, 105-110.

Stromeyer, C. F., III (1972). Contour contingent color aftereffects: Retinal area specificity. American Journal of Psychology, 85, 227235.

STROMEYER, C. F., III (1978). Form-color aftereffects in human vision. In R. Held, H. W. Leibowitz, \& H. L. Teuber (Eds.), Perception. Handbook of sensory physiology (Vol. 8, pp. 97-142). New York: Springer-Verlag.

StROMEYer, C. F., III, \& DAwSON, B. M. (1978). Form-colour aftereffects: Selectivity to local luminance contrast. Perception, 7, 407-415.

WOLFE, J. M., \& RoORDA, J. E. (1990). Long-term visual aftereffects: The by-products of error-correcting mechanisms? Unpublished manuscript.

(Manuscript received July 17. 1996; revision accepted for publication October 15, 1997.) 